\title{
Perceived Health Status of Women with Overt and Subclinical Hypothyroidism
}

\author{
Patrícia Vigário ${ }^{a}$ b Patrícia Teixeira ${ }^{a}$ Vaneska Reuters ${ }^{a}$ Cloyra Almeida ${ }^{a}$ \\ Maicon Maia ${ }^{b}$ Marina Silva ${ }^{a}$ Mário Vaisman ${ }^{a}$ \\ aEndocrinology Service of Clementino Fraga Filho University Hospital and ' $P$ Physical Education School, \\ Federal University of Rio de Janeiro, Rio de Janeiro, Brazil
}

\section{Key Words}

Hypothyroidism $\cdot$ Health status $\cdot$ Quality of life $\cdot$ SF-36

\begin{abstract}
Objective: The objective of this study was to investigate the health status of women with overt and subclinical hypothyroidism and relate it to the presence of clinical signs and symptoms of the disease. Subjects and Methods: A crosssectional study was conducted on 232 women divided into 3 groups: overt hypothyroidism $(n=14)$; subclinical hypothyroidism $(n=152)$, and controls $(n=66)$. Health status was evaluated by the questionnaire SF-36, and the clinical signs and symptoms of hypothyroidism were assessed with the Billewicz scale modified by Zulewski. The Kruskal-Wallis test followed by the Mann-Whitney U test with Bonferroni correction was applied to compare continuous variables between the groups. To assess the relationship between SF-36 domains and the clinical score, as well as SF-36 domains and serum thyroid-stimulating hormone levels, the Spearman correlation coefficient was calculated. Results: Patients with overt hypothyroidism presented systematically lower scores in all SF-36 domains $(p<0.05)$, both in relation to subclinical hypothyroidism patients and controls. This indicates a great dissatisfaction with health status in this group. Patients with subclinical hypothyroidism presented statistically lower scores in relation to controls with the exception of the roleemotional and bodily pain domains, where although they were not statistically significant, scores were clinically differ-
\end{abstract}

\section{KARGER}

Fax +41613061234

E-Mail karger@karger.ch

www.karger.com
(C) 2009 S. Karger AG, Basel

1011-7571/09/0184-0317\$26.00/0

Accessible online at:

www.karger.com/mpp ent. Highly negative correlations between SF-36 domains and the clinical score were observed in overt hypothyroidism (physical function $r=-0.80, p<0.01$; bodily pain $r=$ $-0.74, p<0.01)$. Conclusion: Overt hypothyroidism seemed to be associated with worse perception of health status, negatively associated with clinical score.

Copyright $\odot 2009$ S. Karger AG, Basel

\section{Introduction}

The thyroid hormones T3 and T4 act directly and indirectly upon almost every organ system of the body. In this way, alterations in serum concentrations of these hormones may negatively affect an individual's health status [1].

Overt hypothyroidism and subclinical hypothyroidism are common thyroid disorders, especially in women. Overt hypothyroidism is defined as an elevated serum thyrotropin, also called thyroid-stimulating hormone (TSH), level with decreased concentrations of circulating thyroid hormones [2]. The association of overt hypothyroidism with a broad range of morbidities is well established in the literature. Such morbidities include fatigue, weight gain, abnormalities of lipid metabolism, neuropsychiatric disorders and impaired cardiac-pulmonary function $[3,4]$. Subclinical hypothyroidism is also defined as an elevated serum TSH level, while free thyroxine (FT4) remains within the normal range [5]. Concep- 
tually, subclinical hypothyroidism is an asymptomatic disease essentially based on biochemical alterations. However, many studies have demonstrated that patients under this condition may have clinical signs and symptoms, besides morbidities, that are suggestive of overt hypothyroidism $[6,7]$.

The presence of chronic conditions and/or multimorbidities contributes to disability via physical, functional and psychological impairments, and they also place limitations on social relationships, consequently diminishing quality of life, health status and well-being [8]. In this context, the aim of this study was to investigate the health status of women with overt and subclinical hypothyroidism and relate it to the presence of clinical signs and symptoms of the disease.

\section{Subjects and Methods}

\section{Study Characteristics and Sample}

A cross-sectional study was conducted with ambulatory patients who attended the endocrine clinic of the Clementino Fraga Filho Hospital of the Federal University of Rio de Janeiro (HUCFF/ UFRJ), Brazil. The 232 women who voluntarily participated in the study were divided into 3 groups: subclinical hypothyroidism $(\mathrm{n}=152)$; overt hypothyroidism $(\mathrm{n}=14)$, and control $(\mathrm{n}=66)$. Subclinical hypothyroidism was defined when high serum TSH $(\geq 4.0 \mu \mathrm{UI} / \mathrm{ml})$ with FT4 within the normal range $(0.8-1.9 \mathrm{ng} / \mathrm{dl})$ was detected twice, with a minimum period of 6 weeks between the 2 measurements. Overt hypothyroidism was diagnosed when serum TSH was also above the upper reference limit with decreased serum FT4 $(<0.8 \mathrm{ng} / \mathrm{dl})$. The control group was composed of women without thyroid diseases, with serum TSH and FT4 levels within the normal reference range. The exclusion criteria for participation of the study were the use of medications that could cause thyroid hormone dysfunction, current hospitalization and history of diseases, even if stable, that could affect thyroid hormone secretion. This study was approved by the ethics committee of HUCFF/UFRJ and written informed consent to participate in the investigation was obtained from all the volunteers.

\section{Measures}

Hormone Measurements. Hormones levels were assessed by commercial immunocheminescence assays (Immulite 2,000; Diagnostic Products Corp., Los Angeles, Calif., USA) in the clinical pathologic laboratory/hormone section of HUCFF/UFRJ.

Clinical Evaluation. Participants were asked about their history of smoking ('yes', 'no' or 'ex-smoker'), menopause and physical activity by an endocrinologist. Individuals were classified as 'active' if, in the past 3 months before the beginning of the study, they were involved in any kind of physical activity program with minimum frequency of 2 times/week and minimum duration of 30 min.

Signs and Symptoms of Hypothyroidism: Clinical Score. Disease-specific morbidity was assessed with the Billewicz scale modified by Zulewski [9], as it has been widely used in studies of hypothyroidism. This scale is composed of 12 items about clinical signs and symptoms of hypothyroidism: periorbital puffiness, constipation, weight gain, cold skin, paresthesia, hoarseness, dry skin, diminished sweating, impaired hearing, coarse skin, slow movements and delayed ankle reflex. The signs and symptoms were quantified as 1 point when they are present, or 0 when absent. Thus, the maximum score permitted was 12 points. Scores of $<3$ points were expected in euthyroid subjects, scores of $\geq 3$ to $<5$ points in patients with subclinical hypothyroidism and scores of $\geq 5$ in patients with overt hypothyroidism. In the present investigation, the sample was classified into 2 categories: normal score $(<3)$ and abnormal score $(\geq 3)$.

Health Status. The SF-36 (Medical Outcomes Study 36 - Item Short-Form Health Survey) was used to assess the health status of the women in its translated and validated Portuguese version [10]. The SF-36 is a generic health status assessment instrument composed of 36 items, divided into 8 scales or dimensions: physical function, general health, vitality, mental health, social function, role-emotional, role-physical and bodily pain. Answers were presented on a Likert scale. The maximum score permitted on each scale was 100 points (highest level of satisfaction with health status) and the minimum was score 0 (highest level of dissatisfaction with health status).

\section{Statistics}

The descriptive analyses were presented as median and interquartile range for numeric variables and as percentages for categorical variables. The distribution of the variables was tested with the Kolmogorov-Smirnov test. Differences in frequencies were tested with the $\chi^{2}$ test. The Kruskal-Wallis test was applied to compare the subgroups in relation to age, body mass index (BMI), serum hormone levels and the 8 domains of SF-36. For the identification of differences between the groups, the Mann-Whitney $\mathrm{U}$ test was applied with Bonferroni correction (values of $\mathrm{p}<0.017$ were considered statistically significant). The internal consistency of the 8 dimensions of SF-36 was assessed with Cronbach's alpha coefficient [11]. To assess the relationship between SF-36 domains and the clinical score, as well as SF-36 domains and serum TSH levels, the Spearman correlation coefficient was calculated [12]. A stratified analysis (TSH and FT4 levels according to the classification of clinical score) was also made in the group of subclinical hypothyroidism. The level of statistical significance adopted was $5 \%(\mathrm{p}<0.05)$. All analyses were performed using the SPSS 13.0 statistical package, version 13.0.

\section{Results}

\section{General Characteristics of the Sample}

Clinical and biochemical characteristics of the sample are presented in table 1 . The groups seemed to be similar in respect to age, BMI, menopause, smoking and sedentarism $(\mathrm{p}>0.05)$.

\section{Signs and Clinical Symptoms of Hypothyoidism:}

Clinical Score

The median score of the control group was 2 points $(25$ th percentile $=1$ and 75 th percentile $=4)$ and $21(32 \%)$ 
Table 1. General characteristics and SF-36 domains scores: median (interquartile range) by subgroup

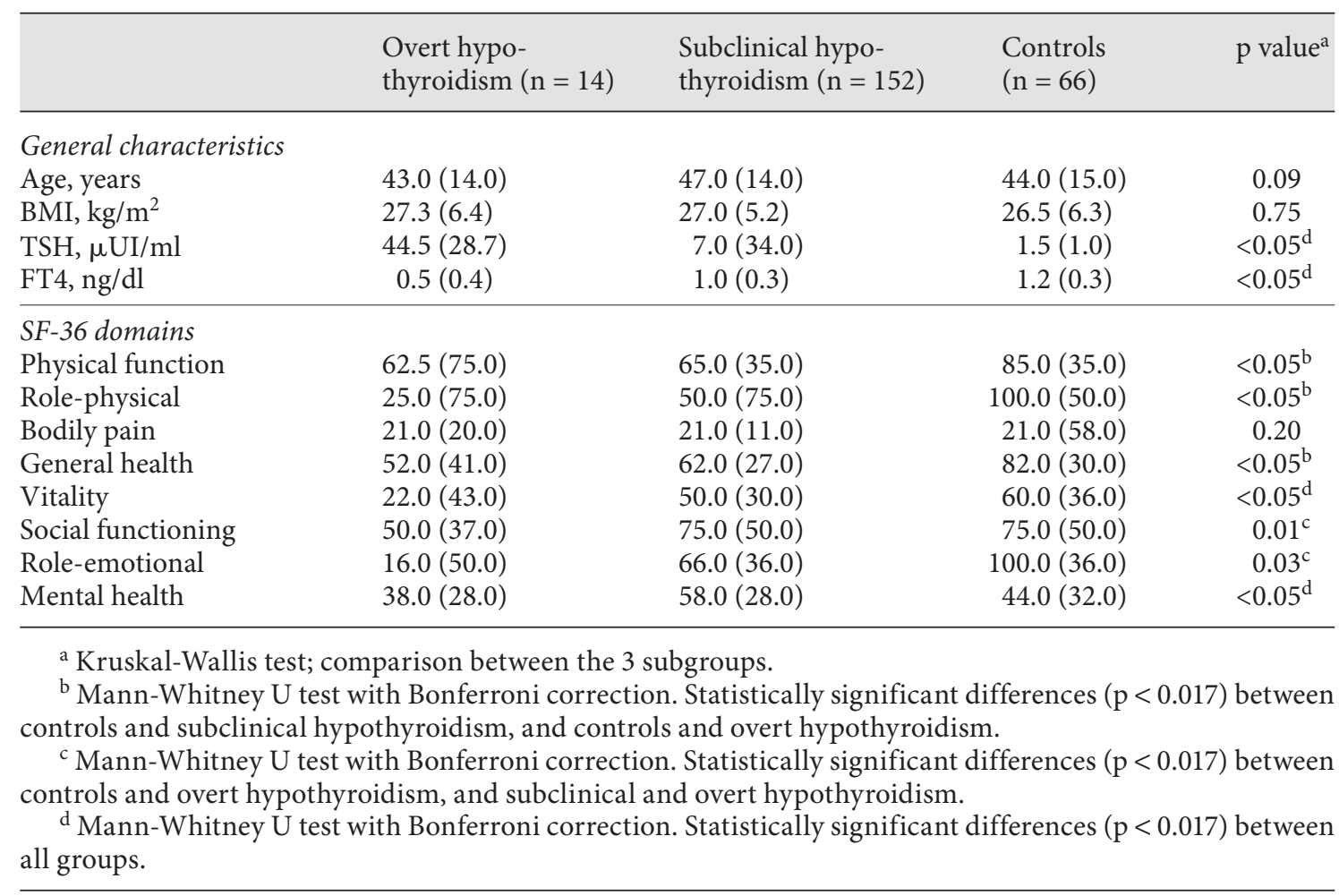

participants of this group had an abnormal score $(\geq 3)$. Among patients with subclinical hypothyroidism, the median score was 4 points (25th percentile $=3$ and 75 th percentile $=5)$, and $114(75 \%)$ patients had scores classified as abnormal. All patients with overt hypothyroidism had scores classified as abnormal, the minimum and maximum scores were 5 and 10 points respectively, and the median was 8 points. The frequency of abnormal scores was statistically different between overt hypothyroidism, subclinical hypothyroidism and control groups $(\mathrm{p}<0.05)$.

Considering the whole group of the study, the clinical score was correlated to TSH $(r=0.33, \mathrm{p}<0.01)$ and to FT4 $(\mathrm{r}=-0.36, \mathrm{p}<0.01)$, with statistical significance. In the overt hypothyroidism patients, the clinical score was correlated to TSH, but did not reach statistical significance $(\mathrm{r}=0.53, \mathrm{p}=0.07)$, while in the subclinical hypothyroidism it was correlated with FT4 $(r=-0.24, p<0.05)$. Finally, in controls, no correlations were found.

\section{Health Status}

All patients completed the SF-36 as requested. The internal consistency of the SF-36 was considered satisfactory $(\alpha=0.9)$, as well as each of its domains with $\alpha$ vary- ing from 0.7 to 0.9 . High internal consistency suggests that the patients of the study reported consistently higher (or lower) levels on questions that correlated well with responses to the other questions of the construct (i.e. health status) or specific domain.

Bodily pain domain, which assessed the frequency of pain and the extent of interference with daily activities due to pain, had the lowest median score (21) in the 3 groups. On the other hand, the groups diverged as for the domain that presented the highest score. Among patients with overt hypothyroidism, the highest median score (62.5) was in the physical function domain, while the patients with subclinical hypothyroidism presented highest median score (75) in the social aspects domain. In the control group, results indicated a higher satisfaction with role-physical and role-emotional domains. At the same time, the group of patients with overt hypothyroidism presented lower scores in the same domains as well as in vitality and bodily pain (table 1 ).

Comparison of the 8 domains between the 3 groups showed that patients with overt hypothyroidism had tendency to lower scores, indicating great dissatisfaction with health status. 
Table 2. Spearman correlation coefficients between SF-36 domains, clinical score and hormone levels, by subgroup

\begin{tabular}{|c|c|c|c|c|c|c|c|c|}
\hline & $\begin{array}{l}\text { Physical } \\
\text { function }\end{array}$ & $\begin{array}{l}\text { Role- } \\
\text { physical }\end{array}$ & $\begin{array}{l}\text { Bodily } \\
\text { pain }\end{array}$ & $\begin{array}{l}\text { General } \\
\text { health }\end{array}$ & Vitality & $\begin{array}{l}\text { Social } \\
\text { functioning }\end{array}$ & $\begin{array}{l}\text { Role- } \\
\text { emotional }\end{array}$ & $\begin{array}{l}\text { Mental } \\
\text { health }\end{array}$ \\
\hline \multicolumn{9}{|c|}{ All participants $(n=232)$} \\
\hline TSH & $-0.16^{\mathrm{a}}$ & $-0.20^{\mathrm{a}}$ & -0.05 & $-0.27^{\mathrm{a}}$ & $-0.19^{\mathrm{a}}$ & -0.07 & -0.12 & $-0.24^{\mathrm{a}}$ \\
\hline FT4 & 0.10 & $0.16^{\mathrm{a}}$ & 0.02 & $0.17^{\mathrm{a}}$ & $0.17^{\mathrm{a}}$ & $0.15^{\mathrm{a}}$ & 0.10 & $0.23^{\mathrm{a}}$ \\
\hline TSH & -0.33 & 0.28 & -0.12 & -0.03 & -0.40 & -0.08 & 0.32 & -0.10 \\
\hline FT4 & 0.31 & 0.20 & 0.47 & 0.37 & 0.32 & 0.08 & -0.04 & 0.27 \\
\hline \multicolumn{9}{|c|}{ Subclinical hypothyroidism $(n=152)$} \\
\hline Clinical score & $-0.21^{\mathrm{a}}$ & -0.17 & $-0.22^{\mathrm{a}}$ & $-0.23^{\mathrm{a}}$ & $-0.35^{\mathrm{a}}$ & -0.11 & -0.14 & $-0.36^{\mathrm{a}}$ \\
\hline \multicolumn{9}{|l|}{ TSH } \\
\hline \multicolumn{9}{|l|}{ FT4 } \\
\hline Normal & $<0.01$ & -0.15 & -0.02 & 0.12 & 0.08 & $<0.01$ & -0.14 & 0.04 \\
\hline \multicolumn{9}{|c|}{ Controls $(n=66)$} \\
\hline Clinical score & $-0.37^{\mathrm{a}}$ & $-0.29^{\mathrm{a}}$ & $-0.35^{\mathrm{a}}$ & $-0.42^{\mathrm{a}}$ & $-0.31^{\mathrm{a}}$ & $-0.39^{\mathrm{a}}$ & $-0.37^{\mathrm{a}}$ & $-0.28^{\mathrm{a}}$ \\
\hline $\mathrm{TSH}$ & -0.09 & -0.06 & 0.10 & 0.09 & 0.02 & -0.11 & -0.15 & -0.06 \\
\hline FT4 & 0.05 & 0.07 & -0.12 & 0.04 & 0.07 & 0.22 & 0.20 & 0.09 \\
\hline
\end{tabular}

\section{Health Status versus Clinical Score}

Negative correlations between all SF-36 domains and the clinical score punctuation were detected in the 3 groups studied. The highly negative correlations were those present in patients with overt hypothyroidism (physical function $\mathrm{r}=-0.80, \mathrm{p}<0.01$; bodily pain $\mathrm{r}=-0.74$, $\mathrm{p}<$ 0.01 ; table 2). In the other groups, we observed weak negative correlations, but with statistical significance.

When SF-36 domains were correlated with the serum TSH level of all participants, we detected weak negative correlations, but which were mostly statistically significant $(\mathrm{p}<0.05)$. Similar tendencies were observed when SF-36 domains were correlated with serum FT4 level, but positively. However, on analyzing each subgroup, it was observed that these correlations lost statistical significance, possibly due to the reduction of the number of subjects analyzed, and none of them presented clinical relevance. In the subgroup of subclinical hypothyroidism these correlations were lost, independently of the presence of abnormal clinical score (table 2).

\section{Discussion}

In this cross-sectional study, subjects with different grades of hypothyroidism were investigated for their perception of their health status and its relation with the presence of signs and clinical symptoms of the disease. Patients with overt hypothyroidism presented systematically lower scores in the domains evaluated by SF-36, thereby pointing to a greater dissatisfaction with health status among this population. Patients with subclinical hypothyroidism occupied an intermediate position between healthy subjects (control group) and patients with overt hypothyroidism. These results suggest the existence of a gradient of deterioration of health status, according to the gravity of the disease.

The main factors and the mechanisms involved in the process of deterioration of quality of life and health status of patients with thyroid dysfunctions are as yet not established. Part of this inconsistency is due to the fact that quality of life is a subjective construct, influenced by factors of several natures and dynamics in time [13]. More- 
over, the use of different methods for diagnosing conditions, measuring quality of life and health status evaluation, besides the lack of comparability between samples, raises difficulties in comparing the studies [14].

Although thyroid-specific instruments such as CTQ and ThyDQoL for evaluating health status are available in the medical literature, we decided to use the SF-36, a generic questionnaire, because both CTQ and ThyDQoL are not yet translated and validated in Portuguese. Equally, the use of a generic questionnaire allows the comparison between healthy and diseased individuals, as well as the identification of the influence on health of comorbidities, which are common in hypothyroidism.

Our findings confirmed previous studies that reported greater dissatisfaction with quality of life in patients with subclinical or overt hypothyroidism compared to controls $[15,16]$. Bianchi et al. [16] further pointed out that patients who presented thyroid dysfunctions, even benign ones, had a worse perception of quality of life than the general population, not only because of the clinical diagnosis itself, but also for the 'label' of being diseased. Similar association has been observed in patients suffering from other chronic diseases [17-19]. Strangely, Watt et al. [20] have observed that patients with overt hypothyroidism or hyperthyroidism seemed to maintain the same perception of quality of life even after restoring the euthyroidism state.

The presence of clinical signs of the disease seemed to exert a fundamental role in the decreasing of health status profile. Hypothyroidism is associated with a high prevalence of clinical symptoms, such as neuromuscular dysfunction, paresthesia, fatigue, dry skin and cold intolerance [21]. Furthermore, psychiatric disturbances like anxiety and depression [22] also have been described [16, 23-25]. Bianchi et al. [16] related that the presence of fatigue and psychiatric disturbances was negatively associated with quality of life scores in patients with overt hypothyroidism. Gerding et al. [23] and Ljunggren et al. [24] noted a relation between less favorable health status scores and the presence of clinical signs in patients with hyperthyroidism. Tagay et al. [25] examined the health status in differentiated thyroid cancer patients under short-term hypothyroidism and observed that it was severely impaired in this population (in comparison to the general population). Also, health status was correlated significantly with worse scores in the scale of signs and symptoms.

Our results confirmed the previously reported association between perceived health status and clinical signs of the disease. This association showed more evidence in overt hypothyroidism, where strong correlations were detected between the domains of SF-36 and the scale of signs and clinical symptoms. This association between clinical signs and health status as noted in our study and previously reported ones have clinical and practical relevance as pointed out by Thompson [26]. However, a study pointed out that women with subclinical hypothyroidism may have the same level of satisfaction with wellbeing, health status and quality of life as healthy women [27].

To our knowledge, this is the first study to examine the relationship between the presence of clinical signs of the disease and the health status in patients with different degrees of hypothyroidism. The most significant finding of the present study was the association between deteriorations in health status of patients and the degree of the disease severity. This fact is very important in daily clinical practice, and so, evaluation of health status may be one more strategy to be incorporated to the routine of clinical evaluation of patients. Endocrinologists' experience reveals that some patients present residual complaints even after the establishment of euthyroidism state by LT- 4 replacement $[28,29]$. It is valuable to emphasize that in the subgroup of subclinical hypothyroidism the correlations between hormone levels and the domains of SF-36 were lost, independently of the presence of abnormal clinical score, which reinforces that the deterioration of health status of those patients is associated with the presence of signs and symptoms of the disease, and not to TSH and FT4 levels.

The quality of life and health status assessment may influence the decision to treat the patient and/or stop a previous replacement. Therefore, it reinforces the idea that adding 'life to years' is as important as adding 'years to life' [30].

The limitations of the present study include: (1) its cross-sectional nature that did not allow for investigating the causality of these relationships; (2) data were based on self-report that could be a potential source of bias; (3) the sample size in the 3 groups was not equal, probably due to the higher prevalence of subclinical hypothyroidism in the general population [31]. Nevertheless, independently of the presence of statistical significance, the results obtained are clinically relevant because the groups presented different profiles of perceived health status, emphasizing that overt hypothyroidism patients presented lower scores either in relation to subclinical hypothyroidism or controls. 


\section{Conclusion}

In the present study, overt hypothyroidism seemed to be associated with worse perception of health status and negatively associated with clinical score. Additional clinical randomized trials are necessary particularly for decision-making that may improve the quality of life, the well-being and the health status of these subjects.

\section{References}

1 Osman F, Gammage MD, Franklyn JA: Thyroid disease and its treatment: short-term and long-term cardiovascular consequences. Curr Opin Pharmacol 2001;6:626-631.

2 Franklyn JA: Hypothyroidism. Medicine 2005;33:27-29.

- 3 Roos A, Linn-Rasker SP, van Domburg RT, Tijssen JP, Berghout A: The starting dose of levothyroxine in primary hypothyroidism treatment: a prospective, randomized, double-blind trial. Arch Intern Med 2005;165: 1714-1720.

-4 Appelhof BC, Fliers E, Wekking EM, Schene $\mathrm{AH}$, Huyser J, Tijssen JG, Endert E, van Weert HC, Wiersinga WM: Combined therapy with levothyroxine and liothyronine in two ratios, compared with levothyroxine monotherapy in primary hypothyroidism: a double-blind, randomized, controlled clinical trial. J Clin Endocrinol Metab 2005;90: 2666-2674.

5 Rodondi N, Aujesky D, Vittinghoff E, Cornuz J, Bauer DC: Subclinical hypothyroidism and the risk of coronary heart disease: a meta-analysis. Am J Med 2006;119:541-551.

-6 Rodondi N, Newman AB, Vittinghoff E, Rekeneire N, Satterfield S, Harris TB, Bauer DC: Subclinical hypothyroidism and the risk of heart failure, other cardiovascular events, and death. Arch Intern Med 2005; 165:2460 2466.

-7 Tuzcu A, Bahceci M, Gokalp D, Tuzun Y, Gunes K: Subclinical hypothyroidism may be associated with elevated high-sensitive creactive protein (low grade inflammation) and fasting hyperinsulinemia. Endocr J 2005;52:89-94

$\checkmark 8$ Fleck MPA, Leal OF, Louzada S, Xavier M, Chachamovich E, Vieira G, Santos L, Pinzon V: Aplicação da versão em português do instrumento abreviado de avaliação da qualidade de vida 'WHOQOL-Bref'. Rev Sau Publ 2000;34:178-183.

9 Zulewski H, Muller B, Exer P, Miserez AR, Staub JJ: Estimation of tissue hypothyroidism by a new clinical score: evaluation of patients with various grades of hypothyroidism and controls. J Clin Endocrinol Metab 1997;82:771-776.

10 Ciconelli RM, Ferraz MB, Santos W, Meinão I, Quaresma MR: Brazilian-Portuguese version of the SF-36: a reliable and valid quality of life outcome measure. Rev Bras Reumatol 1999;39:143-150.
11 Cortina JM: What is Coefficient Alpha? An $\$ 22$ Gonen MS, Kisakol G, Cilli AS, Dikbas O, examination of theory and applications. J Appl Physiol 1993;78:98-104.

12 Altman DG: Practical Statistics for Medical Research. London, Chapman and Hill, 1991.

13 Minayo MCS, Hartz ZMA, Buss PM: Qualidade de vida e saúde: um debate necessário. Cien Saud Colet 2000;5:7-18

$>14$ Razvi S, Ingoe L, Keeka G, Oates C, McMillan C, Weaver JU: The beneficial effect of l-thyroxine on cardiovascular risk factors, endothelial function, and quality of life in subclinical hypothyroidism: randomized, crossover trial. J Clin Endocrinol Metab 2007;92:1715-1723.

15 Gulseren S, Gulseren L, Hekimsoy Z, Cetinay P, Ozen C, Tokatlioglu B: Depression, anxiety, health-related quality of life, and disability in patients with overt and subclinical thyroid dysfunction. Arch Med Res 2006;37:133-139.

16 Bianchi GP, Zaccheroni V, Solaroli E, Vescini F,Cerutti R, Zoli M, Marchesini G: Health related quality of life in patients with thyroid disorders. Qual Life Res 2004;13:45-54.

- 17 Banegas JR, Guallar-Castillon P, RodriguezArtalejo F, Graciani A, Lopez-Garcia E, Ruilope LM: Association between awareness, treatment, and control of hypertension, and quality of life among older adults in Spain. Am J Hypertens 2006;19:686-693.

18 Mena-Martin FJ, Martin-Escudero JC, Simal-Blanco F, Carretero-Ares JL, ArzuaMouronte D, Herreros-Fernandez V: Healthrelated quality of life of subjects with known and unknown hypertension: results from the population-based Hortega study. J Hypertens 2003;21:1283-1289.

19 Sprangers MA, Regt EB, Andries F, Agt HM, Bijl RV, Boer JB, Foets M, Hoeymans N, Jacobs AE, Kempen GI, Miedema HS, Tijhuis MA, Haes HC: Which chronic conditions are associated with better or poorer quality of life? J Clin Epidemiol 2000;53:895-907.

20 Watt T, Groenvold M, Rasmussen AK, Bonnema SJ, Hegedus L, Bjorner JB, FeldtRasmussen U: Quality of life in patients with benign thyroid disorders. A review. Eur J Endocrinol 2006;154:501-510.

21 Reuters VS, Teixeira PFS, Castro CLN, Almeida CP, Cardoso HR, Porciúncula IM, Nobre THS, Reis FAA, Buescu A, Vaisman M: Skeletal muscle dysfunction in patients with subclinical hypothyroidism. Acta Fisiat 2003;10:7-11. Gungor K, Inal A, Kaya A: Assessment of anxiety in sublinical thyroid disorders. Endocr J 2004;51:311-315. Koornneef L, Prummel MF, Wiersinga WM: Quality of life in patients with Graves' ophthalmopathy is markedly decreased: measurement by the medical outcomes study instrument. Thyroid 1997;7:885-889.

24 Ljunggren JG, Torring O, Wallin G, Taube A, Tallstedt L, Hamberger B, Lundell G: Quality of life aspects and costs in treatment of Graves' hyperthyroidism with antithyroid drugs, surgery, or radioiodine: results from a prospective, randomized study. Thyroid 1998;8:653-659.

25 Tagay S, Herpertz S, Langkafel M, Erim Y, Bockisch A, Senf W, Gorges R: Health-related quality of life, depression and anxiety in thyroid cancer patients. Qual Life Res 2006; 15:695-703.

26 Thompson B: 'Statistical', 'practical', and 'clinical': how many kinds of significance do counselors need to consider? J Couns Develop 2002;80:64-71.

27 Bell RJ, Rivera-Woll L, Davison SL, Topliss DJ, Donath S, Davis SR: Well-being, healthrelated quality of life and cardiovascular disease risk profile in women with subclinical thyroid disease: a community-based study. Clin Endocrinol (Oxf) 2007;66:548-556.

28 Saravanan P, Chau WF, Roberts N, Vedhara K, Greenwood R, Dayan CM: Psychological well-being in patients on 'adequate' doses of l-thyroxine: results of a large, controlled community-based questionnaire study. Clin Endocrinol (Oxf) 2002;57:577-585.

29 Walsh JP: Dissatisfaction with thyroxine therapy: could the patients be right? Curr Opin Pharmacol 2002;2:717-722.

30 Fleck MPA, Leal OF, Louzada S, Xavier M, Chachamovich E, Vieira G, Santos L, Pinzon $\mathrm{V}$ : Desenvolvimento da versão em português do instrumento de avaliação de qualidade de vida da OMS (WHOQOL-100). Rev Bras Psiq 1999;21:19-28.

31 Hollowell JG, Staehling NW, Flanders WD, Hannon WH, Gunter EW, Spencer CA, Braverman LE: Serum TSH, T4, and thyroid antibodies in the United States population (1988 to 1994): National Health and Nutrition Survey (NHANES III). J Clin Endocrinol Metab 2002;2:488-499.
23 Gerding, MN, Terwee CB, Dekker FW, 